\title{
Association between the rs6950982 polymorphism near the SERPINE1 gene and blood pressure and lipid parameters in a high-cardiovascular-risk population: interaction with Mediterranean diet
}

\author{
Mercedes Sotos-Prieto • Marisa Guillén • \\ Olga Portolés · José V. Sorlí · José I. González • \\ Eva M. Asensio • Dolores Corella
}

Received: 25 July 2012 / Accepted: 23 November 2012/Published online: 9 December 2012

(c) Springer-Verlag Berlin Heidelberg 2012

\begin{abstract}
The SERPINE1 (serpin peptidase inhibitor, clade E, member 1) gene, better known by its previous symbol PAI-1 (plasminogen activator inhibitor 1), has been associated with cardiovascular phenotypes with differing results. Our aim was to examine the association between the rs6950982 (G > A) near the SERPINE1 gene, blood pressure (BP) and plasma lipid concentrations as well as the modulation of the polymorphism effects by adherence to Mediterranean diet (AMD). We studied 945 high-cardiovascular-risk subjects. Biochemical, clinical, dietary and genetic data (rs6950982) were obtained. We also determined the common rs1799768 (4G/5G), for checking independent effects. AMD was measured by a validated questionnaire, and four groups were considered. rs6950982 $(\mathrm{A}>\mathrm{G})$ and rs1799768 (4G/5G) were only in moderatelow linkage disequilibrium $\left(D^{\prime}=0.719 ; r^{2}=0.167\right)$. The most significant associations we obtained were with rs6950982 (A > G). In males, the $G$ allele was nominally associated with higher diastolic BP (AA: $81.5 \pm 10.9$, AG: $82.1 \pm 11.4$, GG: $\left.85.7 \pm 10.5 \mathrm{mmHg} ; P_{\text {additive }}=0.030\right)$
\end{abstract}

M. Sotos-Prieto · M. Guillén · O. Portolés ·

J. V. Sorlí · J. I. González · E. M. Asensio · D. Corella ( $\square)$

Genetic and Molecular Epidemiology Unit,

Department of Preventive Medicine and Public Health,

School of Medicine, University of Valencia, Blasco Ibañez,

15, 46010 Valencia, Spain

e-mail: dolores.corella@uv.es

M. Sotos-Prieto · M. Guillén · O. Portolés ·

J. V. Sorlí · J. I. González - E. M. Asensio · D. Corella

CIBER Fisiopatología de la Obesidad y Nutrición,

Valencia, Spain

J. V. Sorlí

Consellería de Sanidad, Centro de Salud de Chirivella,

Generalitat Valenciana, Valencia, Spain and systolic BP (AA + AG: $141.4 \pm 6.9 \mathrm{mmHg}$ vs. GG: $149.8 \pm 8.0 \mathrm{mmHg} ; \quad P_{\text {recessive }}=0.036$ ). In the whole population, the rs6950982 was also associated with plasma lipids. Subject with the $G$ allele presented higher total cholesterol $\left(P_{\text {additive }}=0.016, \quad P_{\text {recessive }}=0.011\right)$, lowdensity lipoprotein cholesterol $\left(P_{\text {additive }}=0.032\right.$, $\left.P_{\text {recessive }}=0.031\right)$ and triglycerides $\left(P_{\text {additive }}=0.040\right.$, $\left.P_{\text {recessive }}=0.029\right)$. AMD modulated the effect of rs6950982 on triglyceride concentrations ( $P$ for interaction $=0.036$ ). Greater AMD reduced the higher triglyceride concentrations in GG subjects. No significant interactions were found for the other parameters. The rs6950982 was associated with higher BP in men and higher triglycerides in the whole population, this association being modulated by AMD.

Keywords Nutrigenetics - Genetics - Cardiovascular . Mediterranean diet $\cdot$ Blood pressure $\cdot$ Lipids

\section{Introduction}

Several studies have demonstrated that a higher adherence to the Mediterranean diet has a beneficial effect on cardiovascular diseases (Trichopoulou et al. 2003; Buckland et al. 2009; Fung et al. 2009; Martínez-González et al. 2011). In a pilot study (Estruch et al. 2006), we have shown that after a 3-month intervention with Mediterranean diet, this intervention produced beneficial changes in several cardiovascular risk factors compared with a low-fat diet. Outstanding among them were the significant reductions in systolic and diastolic blood pressure (BP). We also observed favorable changes in plasma lipids (Estruch et al. 2006). Taking into account that there were very few studies aimed at examining gene-diet interactions between 
adherence to Mediterranean diet and genetic polymorphisms in determining blood pressure, we were interested in searching for polymorphisms associated with BP which may also be associated with plasma lipid concentrations, as well as studying how these associations could be modulated by greater or lesser adherence to the Mediterranean diet. One of the first genome-wide association studies (GWAs) focused on BP and carried out in the Framingham Study (Levy et al. 2007) showed that the intergenic rs6950982 near the SERPINE1 (serpin peptidase inhibitor, clade E, member 1) gene was one of the polymorphisms most significantly associated with BP. This polymorphism was located in a region that has been linked to arterial hypertension (Brown et al. 2001; Poli et al. 2000; Eliasson et al. 1997). Moreover, this region has also been linked to lipid concentrations (Arya et al. 2002; Duggirala et al. 2000). The SERPINE1 gene, better known by its previous symbol PAI-1 (plasminogen activator inhibitor 1), located at chromosome 7q22 (Klinger et al. 1987), is a relevant marker for fibrinolysis. It has been demonstrated that PAI protein activity is correlated with plasma insulin and triglyceride (TG) concentrations in subjects with hypertension (Landin et al. 1990). In addition, one study found an interactive effect of endogenous angiotensin II and aldosterone on PAI production (Sawathiparnich et al. 2003), and there are several works analyzing the concurrent effects of the PAI protein in renal and cardiovascular diseases (Ha et al. 2009). One of the polymorphisms most studied in the SERPINE1 gene has been the $4 \mathrm{G} / 5 \mathrm{G}$. This promoter polymorphism has been considered as a risk factor for cardiovascular diseases (Kohler and Grant 2000; Li 2012; Gong et al. 2012) and has been associated with lipid parameters (Ruiz-Quezada et al. 2004; Boncoraglio et al. 2006; Kinik et al. 2008; Al-Hamodi et al. 2012), thrombosis (Seguí et al. 2000; Gohil et al. 2009; Akhter et al. 2010), obesity (Berberoğlu et al. 2006; Kinik et al. 2008), and myocardial infarction (Hindorff et al. 2002; Ossei-Gerning et al. 1997; Adamski et al. 2009; Gong et al. 2012). In addition, it has also been described as a potential candidate for hypertension (Kobashi et al. 2009; MartínezCalatrava et al. 2007; Björck et al. 2011; Kim et al. 2012). However, there are no published studies regarding the rs6950982 polymorphism in which the association between this variant and blood pressure and lipid parameters has been examined. Taking into account that the initial observation of the association between the rs6950982 near the SEPINE1 gene and blood pressure in the Framingham Study has not been replicated in subsequent GWAs, this may be due to a potential interaction with environmental factors such as diet that could mask the effect of the genotype on this trait.

Therefore, our objectives were (1) to study the association between the rs6950982 polymorphism in the
SERPINE1 gene and the blood pressure in a high-cardiovascular-risk Mediterranean population, (2) to analyze the association between this polymorphism and lipid parameters, (3) to explore the linkage of disequilibrium between the rs6950982 and the $4 \mathrm{G} / 5 \mathrm{G}$ PAI- 1 polymorphisms, and (4) to analyze the modulation of the rs6950982 effects by adherence to the Mediterranean diet.

\section{Methods}

Subjects and study design

We studied 945 consecutive subjects (340 men and 605 women) aged 55-80 years who participated in the PREvención con DIeta MEDiterránea (PREDIMED) Study in the Valencia Region, Spain, from October 2003 to September 2008. All these subjects had the SERPINE1 polymorphism determined and valid data for other anthropometric, biochemical and lifestyle variables. The PREDIMED study is a multi-center clinical trial aimed at assessing the effects of the Mediterranean diet on the primary prevention of cardiovascular disease. Details of this study have been reported elsewhere (Estruch et al. 2006). In this report, we present data of a cross-sectional analysis at baseline including potential high-cardiovascular-risk subjects selected by physicians in primary care centers affiliated to teaching hospitals in the Valencia region. Eligible subjects were community-dwelling people (55-80 years of age for men; 60-80 years of age for women) who fulfilled at least one of two criteria: type 2 diabetes; 3 or more cardiovascular risk factors: current smoking, hypertension (blood pressure $\geq 140 / 90 \mathrm{mmHg}$ or treatment with antihypertensive drugs), low-density lipoprotein cholesterol (LDL-C) $\geq 160 \mathrm{mg} / \mathrm{dl}$ (or treatment with hypolipidemic drugs), high-density lipoprotein cholesterol $\left(\right.$ HDL-C) $\leq 40 \mathrm{mg} / \mathrm{dl}$, body mass index $(\mathrm{BMI}) \geq 25 \mathrm{~kg} / \mathrm{m}^{2}$ or a family history of premature CHD. Exclusion criteria included a personal history of cardiovascular disease, any severe chronic illness and drug or alcohol addiction (Estruch et al. 2006). The Institutional Review Board of the Valencia University approved the study protocol, and all participants provided written informed consent.

Anthropometric, clinical, biochemical and lifestyle data

The baseline examination included assessment of standard cardiovascular risk factors, medication use and sociodemographic factors. Height and weight were measured with light clothing and no shoes. BMI was calculated as the weight (in $\mathrm{kg}$ ) divided by the height (in $\mathrm{m}^{2}$ ). Obesity was defined as a BMI $\geq 30 \mathrm{~kg} / \mathrm{m}^{2}$ and overweight as a BMI of $25-29.9 \mathrm{~kg} / \mathrm{m}^{2}$ in accordance with World Health Organization (WHO) criteria. Blood pressure was measured by 
trained personnel using a validated semi-automatic oscillometer (Omron HEM-70CP; Hoofddrop, the Netherlands) with the subject seated, following the procedures recommended by the Spanish Hypertension Society. Measurements were carried out in triplicate with a 5-min interval between each, and the mean of these values was recorded. Fasting blood samples were obtained for each participant and stored at $-80{ }^{\circ} \mathrm{C}$ until biochemical analyses. Fasting glucose, total cholesterol (TC), TG, HDL-C and LDL-C were determined as previously reported (Estruch et al. 2006). Plasma glucose was analyzed by the glucose-oxidase method, triglycerides and TC were measured using standard enzymatic procedures, and HDL-C concentrations were estimated after precipitation with phosphotungstic acid and magnesium chloride. LDL-C concentrations were estimated with the equation of Friedewald et al. whenever triglycerides were $<400 \mathrm{mg} / \mathrm{dl}$. Physical activity was estimated by the Minnesota Leisure Time Physical Activity questionnaire (Elosua et al. 2000).

\section{Dietary intake}

Food consumption was determined by a previously validated semi-quantitative 137-item food frequency questionnaire (Fernández-Ballart et al. 2010). Energy and nutrient intake were calculated from Spanish food composition tables (Mataix 2003). The baseline examination also included the administration of a validated 14-item questionnaire indicating the degree of adherence to the traditional Mediterranean diet (Schröder et al. 2011). Values of 0 or 1 were assigned to each of 14 dietary components. The greater the score obtained from the questionnaire, the greater the adherence to the Mediterranean diet. We created four groups according to the points obtained in the questionnaire of adherence to Mediterranean diet; therefore, the first group had the lowest adherence to Mediterranean diet and the fourth group the highest: Group 1 (G1: 3-6 points, $15.6 \%)$; Group 2 (G2: 7-8 points; $35.2 \%$ ); Group 3 (G3: 9-10 points; $32.6 \%$ ); and Group 4 (11-14 points; $16.6 \%)$.

\section{Genetic analyses}

Genomic DNA was extracted from buffy coat with the MagNaPure LC DNA Isolation kit (ROCHE Diagnostics). The rs6950982 polymorphism in the SERPINE1 gene was genotyped on a 7900HT Sequence Detection system (Applied Biosystems) using a fluorescent allelic discrimination TaqMan assay by standard procedures. For quality control purposes, $10 \%$ of randomly selected samples were genotyped a second time. There were no discrepancies between the two results. Genotype frequencies were consistent with Hardy-Weinberg equilibrium $(P=0.09)$.
The PAI-1 promoter $4 \mathrm{G} / 5 \mathrm{G}$ polymorphism was analyzed using an allele-specific PCR technique with several modifications (Grancha et al. 1999). Electrophoresis was performed in $3 \%$ high-resolution agarose MS-4. Photographic records were obtained after ethidium bromide staining.

\section{Statistical analysis}

Chi-square tests were used to compare proportions. Triglycerides concentrations were log-transformed for the statistical analyses. $t$ tests and ANOVA tests were applied to compare crude means. Dominant, co-dominant and recessive models of inheritance were first tested to know the effects of the variant allele. In the analysis for the additive model, the SERPINE1 polymorphism was considered as a linear term coded as 0,1 or 2 depending of the number of variant alleles, with the homozygote wild type coded as 0 . In this model, each variant allele contributes additively to the phenotype. Despite this higher effect in homozygous subjects for the variant allele, for some traits, a recessive model (AA + AG) versus GG was more significant. Results were presented both for the additive and for the recessive models. In order to increase statistical significance, the recessive model was only considered for the analysis of gene-diet interactions.

Crude models were adjusted for potential confounders by covariance analysis. Models were adjusted for age, gender and medications (lipid-lowering and antihypertensive drugs). To study the linkage disequilibrium between the rs6950982 and the $4 \mathrm{G} / 5 \mathrm{G}$, we used HaploView. To study gene-diet interactions in determining triglycerides, we used multivariate linear regression models including main effects and interaction terms and controls for sex, age and obesity. The homogeneity of the effects by gender was also statistically tested. Statistical analyses were performed with the SPSS package, version 15.0 (SPSS, Chicago, IL). All tests were two-tailed, and $P$ values $<0.05$ were considered statistically significant at the nominal value.

\section{Results}

General characteristics of the studied population

We studied subjects with high cardiovascular risk from a Mediterranean population with a mean age of $67.3 \pm 6.2$ years. Anthropometric, clinical, biochemical and genetic characteristics of the 945 participants by gender (340 men and 605 women) are presented in Table 1 . Minor allele frequency for the $r s 6950982$ polymorphism in the SERPINE1 gene was 0.22. Adherence to the Mediterranean diet measured by a Mediterranean diet score 
Table 1 Anthropometric, clinical, biochemical, lifestyle and genetic characteristics of participants

\begin{tabular}{|c|c|c|c|c|}
\hline Variables & Total $(n=945)$ & Male $(n=340)$ & Female $(n=605)$ & $P^{*}$ \\
\hline Age (years) & $67.3 \pm 6.2$ & $66.8 \pm 5.9$ & $67.60 \pm 6.6$ & 0.053 \\
\hline $\operatorname{BMI}\left(\mathrm{kg} / \mathrm{m}^{2}\right)$ & $30.9 \pm 5.1$ & $29.4 \pm 4$ & $31.7 \pm 5.2$ & $<0.001$ \\
\hline $\mathrm{TC}(\mathrm{mg} / \mathrm{dl})$ & $208 \pm 40$ & $200 \pm 38$ & $212 \pm 40$ & $<0.001$ \\
\hline HDL-C (mg/dl) & $53 \pm 14$ & $49 \pm 12$ & $56 \pm 14$ & $<0.001$ \\
\hline LDL-C (mg/dl) & $129 \pm 36$ & $124 \pm 37$ & $131 \pm 36$ & 0.004 \\
\hline $\mathrm{TG}(\mathrm{mg} / \mathrm{dl})$ & $131 \pm 81$ & $137 \pm 74$ & $127 \pm 84$ & 0.025 \\
\hline Fasting glucose (mg/dl) & $123 \pm 40$ & $129 \pm 42$ & $119 \pm 39$ & 0.001 \\
\hline $\mathrm{SBP}(\mathrm{mmHg})$ & $147 \pm 22$ & $147 \pm 21$ & $146 \pm 23$ & 0.655 \\
\hline $\mathrm{DBP}(\mathrm{mmHg})$ & $82 \pm 11$ & $82 \pm 11$ & $81 \pm 11$ & 0.498 \\
\hline MD adherence score & $8.48 \pm 2.0$ & $8.6 \pm 2.0$ & $8.4 \pm 2.0$ & 0.097 \\
\hline Diabetes (\%) & 48.5 & 56 & 44.3 & 0.001 \\
\hline Hypertension (\%) & 79.7 & 71.4 & 84.4 & $<0.001$ \\
\hline Anti-hypertensive agents (\%) & 66.7 & 57.3 & 71.9 & $<0.001$ \\
\hline Current smokers $(\%)$ & 11.9 & 26.7 & 3.6 & $<0.001$ \\
\hline SERPINE1 A > G (rs6950982) polymorphism & & & & 0.09 \\
\hline AA $(n=566)$ & 60.5 & 61.4 & 60.9 & \\
\hline $\mathrm{AG}(n=320)$ & 34.2 & 31.3 & 35.0 & \\
\hline $\mathrm{GG}(n=49)$ & 5.2 & 7.2 & 4.1 & \\
\hline
\end{tabular}

Values are presented as mean \pm standard deviation for continuous variables or $\%$ for categorical variables

$B M I$ Body mass index, $T C$ total cholesterol, $T G$ triglyceride, $S B P$ systolic blood pressure, $D B P$ diastolic blood pressure, $H D L-C$ high-density lipoprotein cholesterol, $L D L-C$ low-density lipoprotein cholesterol, $M D$ Mediterranean diet

* $P$ value for comparisons between males and females

ranging form 0 ( $\min )$ to 14 (max) was slightly higher in males than in females without reaching the statistical significance. For statistical analysis, we considered four groups of increasing adherence to the Mediterranean diet as detailed in "Methods".

Association between rs6950982 polymorphism, $\mathrm{BP}$ and plasma lipid parameters

Table 2 shows the results of the association between the SERPINE1 rs6950982 polymorphism and BP and plasma lipid parameters in the whole population. Mean values for the corresponding parameter according to SERPINE1 rs6950982 are displayed. Crude and multivariate-adjusted $P$ values for each parameter are shown. First, additive effects were estimated considering the presence of 0,1 or 2 variant alleles. In addition, we estimated the association using a recessive model. We observed statistically significant association at the nominal level between the SERPINE1 rs6950982 polymorphism and total TC, LDL-C and TG in both the additive and the recessive models. Thus, this SERPINEI SNP was significantly associated with TC (AA: $208 \pm 41 \mathrm{mg} / \mathrm{dl}$, AG: $210 \pm 37$, GG: $218 \pm 48 \mathrm{mg} / \mathrm{dl}$ ), LDL-C (AA: $127 \pm 36$, AG: $131 \pm 34$, GG: $136 \pm 44 \mathrm{mg} / \mathrm{dl}$ ) and TG concentrations (AA: $131 \pm 69$, AG: $128 \pm 67$, GG: $154 \pm 111 \mathrm{mg} / \mathrm{dl}$ ), the GG having higher concentrations after multivariate adjustment for sex, age and lipid-lowering agents $\left(P_{\text {additive }}=0.016\right.$ and $P_{\text {recessive }}=0.011$, $P_{\text {additive }}=0.032$ and $P_{\text {recessive }}=0.031, P_{\text {additive }}=0.040$ and $P_{\text {recessive }}=0.029$, respectively) (Table 2 ). Although the association with TG was statistically significant (at nominal level) under the additive and under the recessive models, when we examined the differences in means between $\mathrm{AA}$ and $\mathrm{AG}$ subjects, we observed that the recessive model for this trait was more adequate and statistically significant $(P=0.029)$ than the additive model $(P=0.40)$.

No associations were found between the genotype and the systolic and diastolic BP (Table 2) in the whole population. However, we observed heterogeneity by gender in these traits and conducted stratified analysis by gender. Thus, in males (Table 3), after adjustment by age and antihypertensive agents, the $\mathrm{G}$ allele was associated with higher diastolic BP (AA: $81.5 \pm 10.9$, AG: $82.1 \pm 11.4$, GG: $85.7 \pm 10.5 \mathrm{mmHg} ; \quad P=0.030)$ in the additive model. Moreover, we also observed a significant association at the nominal level with higher systolic BP when the recessive model was considered (AA + AG: $141.4 \pm$ $6.9 \mathrm{mmHg}$ vs. GG: $149.8 \pm 8.0 \mathrm{mmHg} ; \quad P_{1}=0.036$ ). Moreover, in the stratified analysis, we found that the association of the SERPINE1 rs6950982 polymorphism with TC and LDL-C was highly significant in men.

We also analyzed prevalence of hypertension, and we did not find significant association with the GG genotype 
Table 2 Clinical parameters in the whole population (men and women) depending on the rs6950982 SERPINE1 polymorphism

\begin{tabular}{|c|c|c|c|c|c|c|}
\hline & AA $(n=566)$ & $\mathrm{AG}(n=320)$ & GG $(n=49)$ & $P^{*}$ & $P^{* *}$ & $P^{\wedge}$ \\
\hline Age (years) & $67.2 \pm 6.2$ & $67.6 \pm 6.1$ & $68.2 \pm 6.8$ & 0.724 & 0.690 & 0.256 \\
\hline Score to MD adherence & $8.5 \pm 2.0$ & $8.4 \pm 2.0$ & $8.5 \pm 1.8$ & 0.989 & 0.526 & 0.968 \\
\hline $\mathrm{SBP}(\mathrm{mmHg})$ & $146.5 \pm 22.0$ & $146.3 \pm 23.0$ & $151.1 \pm 19.5$ & 0.327 & 0.956 & 0.208 \\
\hline $\mathrm{DBP}(\mathrm{mmHg})$ & $81.2 \pm 10.4$ & $82.1 \pm 11.7$ & $82.0 \pm 11.2$ & 0.129 & 0.365 & 0.583 \\
\hline $\mathrm{TC}(\mathrm{mg} / \mathrm{dl})$ & $208 \pm 41$ & $210 \pm 37$ & $218 \pm 48$ & 0.039 & 0.016 & 0.011 \\
\hline HDL-C (mg/dl) & $53 \pm 14$ & $54 \pm 13.3$ & $52 \pm 13$ & 0.367 & 0.915 & 0.911 \\
\hline LDL-C (mg/dl) & $127 \pm 36$ & $131 \pm 34$ & $136 \pm 44$ & 0.065 & $\mathbf{0 . 0 3 2}$ & 0.031 \\
\hline TG (mg/dl) & $131 \pm 69$ & $128 \pm 67$ & $154 \pm 111$ & 0.013 & 0.040 & 0.029 \\
\hline Fasting glucose (mg/dl) & $123 \pm 41$ & $123 \pm 42$ & $122 \pm 40$ & 0.847 & 0.936 & 0.721 \\
\hline Current smokers (\%) & 12.2 & 10.2 & 16.1 & 0.778 & 0.891 & 0.777 \\
\hline Hypertension (\%) & 77.8 & 82.7 & 83.6 & 0.139 & 0.365 & 0.342 \\
\hline
\end{tabular}

Values are presented as mean \pm standard deviation for continuous variables or \% for categorical variables

$M D$ Mediterranean diet, $S B P$ systolic blood pressure, $D B P$ diastolic blood pressure, $T C$ total cholesterol, $T G$ triglyceride, $F G$ fasting glucose, $H D L-C$ high-density lipoprotein cholesterol, $L D L-C$ low-density lipoprotein cholesterol

* $P$ for linear trend (additive effects were estimated including: 0,1 or 2 variant alleles). Unadjusted analysis

** $P$ value for the additive model adjusted by sex, age and anti-hypertensive agents or lipid-lowering agents

$\wedge \quad P$ value for recessive effects adjusted by sex, age and anti-hypertensive agents or lipid-lowering agents

$P$ values in bold indicate statistically significant associations $(P<0.05)$

$(P=0.332)$ because of the low prevalence of subjects without hypertension in this high-cardiovascular-risk population.

Linkage disequilibrium of the rs6950982

polymorphism and the $4 \mathrm{G} / 5 \mathrm{G}$ in the SERPINE1 gene

Genotype distribution for the 4G/5G SNP was in accordance with Hardy-Weinberg equilibrium $(P=0.9)$. The rs6950982 polymorphism and the $4 \mathrm{G} / 5 \mathrm{G}$ were slightly in linkage disequilibrium $\left(D^{\prime}=0.719 ; r^{2}=0.167\right)$ in this Mediterranean population, suggesting that the associations between rs6950982 polymorphism and BP and lipid parameters may be independent of the $4 \mathrm{G} / 5 \mathrm{G}$ polymorphism. However, we also found that the $5 \mathrm{G}$ genotype was significantly associated with diastolic BP in men $(4 \mathrm{G}+4 \mathrm{G} / 5 \mathrm{G}: 81 \pm 10$ vs. $5 \mathrm{G}$ : $86 \pm 13.8 \mathrm{mmHg}, P=0.013$ ). After adjustment by sex, age and antihypertensive agents, this association remained statistically significant $(P=0.047)$. TC and LDL-C concentrations tended to be higher in the $5 \mathrm{G}$ genotype, but did not reach statistical significance $(P=0.282, P=0.296)$. No associations were found for the other parameters analyzed.

Interaction between the rs6950982 polymorphism and adherence to the Mediterranean diet in determining TG concentrations

We tested whether adherence to the Mediterranean diet modified the associations between the rs6950982 and TG

Table 3 Clinical parameters in men depending on the rs6950982 SERPINE1 polymorphism

\begin{tabular}{|c|c|c|c|c|c|c|}
\hline & AA $(n=204)$ & $\mathrm{AG}(n=104)$ & GG $(n=24)$ & $P^{*}$ & $P^{* *}$ & $P^{\wedge}$ \\
\hline MD adherence score & $8.7 \pm 2.1$ & $8.6 \pm 2.0$ & $8.6 \pm 1.8$ & 0.860 & 0.921 & 0.784 \\
\hline $\mathrm{SBP}(\mathrm{mmHg})$ & $146.3 \pm 20.5$ & $147.3 \pm 23.3$ & $155.8 \pm 18.5$ & 0.072 & 0.237 & 0.036 \\
\hline $\mathrm{DBP}(\mathrm{mmHg})$ & $81.5 \pm 10.9$ & $82.1 \pm 11.4$ & $85.7 \pm 10.5$ & $\mathbf{0 . 0 3 0}$ & 0.130 & 0.096 \\
\hline $\mathrm{TC}(\mathrm{mg} / \mathrm{dl})$ & $197 \pm 36$ & $201 \pm 38$ & $225 \pm 44$ & 0.002 & 0.005 & 0.001 \\
\hline LDL-C (mg/dl) & $122 \pm 34$ & $126 \pm 35$ & $147 \pm 45$ & 0.009 & 0.008 & 0.002 \\
\hline $\mathrm{TG}(\mathrm{mg} / \mathrm{dl})$ & $136 \pm 73$ & $137 \pm 69$ & $152 \pm 76$ & 0.090 & 0.377 & 0.232 \\
\hline
\end{tabular}

Values are presented as mean \pm standard deviation for continuous variables

$M D$ Mediterranean diet, $S B P$ systolic blood pressure, $D B P$ diastolic blood pressure, $T C$ total cholesterol, $L D L-C$ low-density lipoprotein cholesterol, $T G$ triglyceride

* $P$ for linear trend (additive effects were estimated including: 0,1 or 2 variant alleles). Unadjusted analysis

** $P$ value for the additive model adjusted for age and anti-hypertensive agents or lipid-lowering agents

${ }^{\wedge} P$ value for recessive model adjusted for age and anti-hypertensive agents or lipid-lowering agents

$P$ values in bold indicate statistically significant associations $(P<0.05)$ 
concentrations according to groups of adherence. Four categories of adherence to Mediterranean diet were considered according to the score obtained in the questionnaire, as indicated in "Methods". We found a statistically significant interaction (nominal $P$ value) between the SERPINE1 rs6950982 polymorphism and adherence to Mediterranean diet in determining TG concentrations ( $P$ for interaction: 0.036 ) (Fig. 1). Means were adjusted by sex, age, lipid-lowering agents, current smoker and diabetes. Among those subjects with lower adherence to Mediterranean diet (G1-G2-G3), the SERPINE1 rs6950982 polymorphism was significantly associated with TG concentrations $(P=0.003)$. In contrast, in the group of higher adherence to the Mediterranean diet, the GG genotype was not significantly associated with higher TG concentrations $(P=0.374)$.

We also tested the potential gene-diet interaction between adherence to the Mediterranean diet (four groups) and the SERPINE1 rs6950982 polymorphism in determining systolic or diastolic blood pressure. However, statistically significant interactions were found ( $P$ for interaction between rs6950982 and adherence to the Mediterranean diet on systolic $\mathrm{BP}=0.629$; and $P$ for interaction between rs6950982 and adherence to the Mediterranean diet on systolic BP $=0.710$ ). We did not detect any significant interaction with adherence to

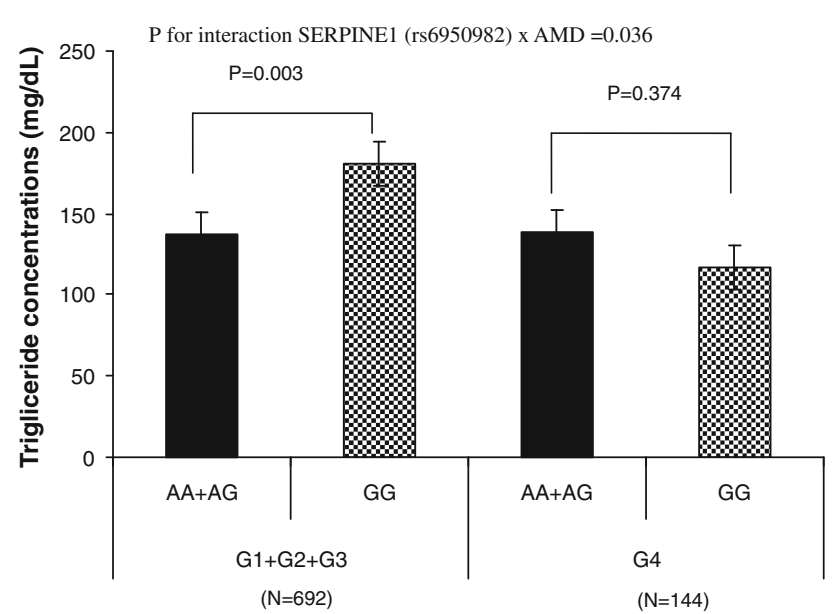

Fig. 1 Gene*diet interaction between adherence to the Mediterranean diet (MD) and the rs6950982 polymorphism in the SERPINE1 gene in determining plasma triglycerides. Adjusted means of triglycerides (TG) are shown depending on the SERPINE1 polymorphism according to the strata of adherence to the Mediterranean diet. Means were adjusted by sex, age, lipid-lowering agents, current smokers and diabetes. $P$ values for interaction terms between triglyceride concentrations and SERPINE1 polymorphism were obtained in the hierarchical multivariate interaction model. TG concentrations were log-transformed for statistical testing. $\mathrm{G} 1+\mathrm{G} 2+\mathrm{G} 3=$ Group 1,2 and 3 of adherence to the MD. $\mathrm{G} 4=$ Group 4 with higher adherence to MD
Mediterranean Diet when the $4 \mathrm{G} / 5 \mathrm{G}$ polymorphism in determining blood pressure or TG was analyzed.

\section{Discussion}

We have investigated the influence of the rs6950982 near the SERPINE1 gene on BP and lipid parameters in a highcardiovascular-risk Mediterranean population. We have found a statistically significant association between $S E R$ PINE1 polymorphism and higher diastolic and systolic BP in men, so replicating previous results from the Framingham Study (Levy et al. 2007) in which additive effects of the rs6950982 in the SERPINE1 on diastolic BP were described. Furthermore, we have found statistically significant associations between this SERPINE1 polymorphism and higher plasma TC, LDL-C and TG concentrations. In the analysis of gene-diet interactions, we also found that the association between the rs6950982 in the SERPINE1 and higher TG concentration in GG subjects is modulated by adherence to the Mediterranean diet. Thus, when adherence to the Mediterranean diet was high (G4), we did not observe the increase in TG in GG subjects. However, when the adherence is low ( $\mathrm{G} 1+$ $\mathrm{G} 2+\mathrm{G} 3$ ), higher TG concentrations were detected in GG subjects in comparison with carriers of the A allele.

This is the first time that this gene-diet interaction is reported, and we do not know the potential mechanisms involved. Recently, it has been published that SERPINE1 gene expression could be under the influence of microRNAs (miRNAs) (Marchand et al. 2012). Likewise, another recent work also suggested that gene-diet interactions as modulators of different cardiovascular phenotypes may act in part through creation of a miRNA regulatory sites (Richardson et al. 2011). More studies are needed to confirm this hypothesis.

Apart from the Framingham Study (Levy et al. 2007), we did not find any other epidemiological study analyzing the effects of this polymorphism in the SERPINE1 gene on $\mathrm{BP}$ and lipid parameters. However, the $4 \mathrm{G} / 5 \mathrm{G}$ polymorphism in the promoter of the SERPINE1 gene has been widely investigated in different studies (Spiroski et al. 2000; Abboud et al. 2010; Rallidis et al. 2010; Lopes et al. 2003; Kobashi et al. 2009, Martínez-Calatrava et al. 2007; Björck et al. 2011; Kim et al. 2012; Boncoraglio et al. 2006; Kinik et al. 2008; Al-Hamodi et al. 2012). In this population, we found that the rs6950982 polymorphism in the SERPINE 1 gene is in slight linkage disequilibrium with the 4G/5G. Therefore, it seems that the observed effect for the rs6950982 is more specific for the rs6950982 locus. However, a linkage disequilibrium effect on blood pressure with the $4 \mathrm{G} / 5 \mathrm{G}$ polymorphism cannot be discarded because we also have found a statistically significant association at 
nominal level between the $4 \mathrm{G} / 5 \mathrm{G}$ polymorphism and BP in our population. There are few studies analyzing the association between $4 \mathrm{G} / 5 \mathrm{G}$ genotype and hypertension, and the results are controversial (Kobashi et al. 2009; MartínezCalatrava et al. 2007; Björck et al. 2011; Kim et al. 2012). A study analyzing the severe pregnancy-induced hypertension (PIH) suggested that PAI-1 4G/4G alone was not a risk factor for $\mathrm{PIH}$, but showed positive associations in combination with other genotypes in other genes (Kobashi et al. 2009). Other studies showed that fibrinolytic markers such as PAI-1, tPA, tPA/PAI-1 complex are independently associated with the development of hypertension, supporting the hypothesis that hypertension may be associated with impaired fibrinolysis (Tabak et al. 2009). However, no consistent associations have been found for this SNP.

Other studies analyzing the SERPINE1 4G/5G polymorphism have indicated that this polymorphism could induce alterations in the genetic expression of PAI-1 levels (Abboud et al. 2010; Schoenhard et al. 2008) affecting the binding of nuclear proteins and regulating PAI-1 transcription (Dawson et al. 1993; Eriksson et al. 1995). It is widely accepted that plasma PAI levels are positively associated with increased risk of artherosclerotic coronary disease (Abboud et al. 2010). In a case control study, it was found that $5 \mathrm{G}$ carriers and the $5 \mathrm{G} 5 \mathrm{G}$ had significantly higher TC, TG and VLDL concentrations (Ruiz-Quezada et al. 2004). These results were in line with those found in our study in carriers of the $G$ allele for the rs6950982 polymorphism. These findings together with our results illustrate the difficulty of analyzing the genotype-phenotype association where environmental factors could modulate the effects of gene polymorphisms. In this sense, there are few studies that investigate the gene-environment interaction involving the PAI-1 polymorphisms. One of these studies was carried out by Pérez-Martínez et al. (2008) on 59 healthy volunteers and showed that carriers of 4G had a decrease in PAI concentrations after a diet rich in MUFA (monounsaturated fatty acids) compared with a diet rich in saturated fat and high carbohydrate. However, the $5 \mathrm{G}$ had lower PAI concentrations, regardless of the diet. The results of our study regarding the gene-diet interaction reveal a modulation of TG concentrations by adherence to the Mediterranean diet that is a diet rich in MUFA, and a similar regulation might be involved. However, this hypothesis is highly speculative, and more research is needed on this potential mechanism.

On the other hand, one limitation of our study is the small sample size. Most of our results only reached statistical significance with nominally significant $P$ values $(P<0.05)$. However, if a correction for multiple comparisons were undertaken, taking into account the Bonferroni approach in which we correct for each one of the traits that are compared (SBP, DBP, TC, LDL-C, HDL-C and TG), the $P$ value that we would have to obtain to consider the results statistically significant would be $0.05 / 6=0.008$. This value is only reached for the association of the polymorphism with higher TC and LDL-C concentrations in men. In addition, our results are also statistically significant $(P<0.008)$ after correction for multiple comparisons when we considered the modulation by the adherence to the Mediterranean diet. Thus, the association between the rs6950982 polymorphism and plasma TG concentrations was statistically significant $(P=0.003)$ in the three groups of less adherence to the Mediterranean diet, whereas we did not find association $(P>0.05)$ in the group of higher adherence to the Mediterranean diet.

In conclusion, we have found that rs6950982 near the SERPINE1 gene is associated with TC, LDL-C, TG and BP (in men) in a high risk Mediterranean population and that the adherence to Mediterranean diet may modulate the association with TG. However, taking into account that this is the first time that this interaction is reported as well as sample size limitations, more studies are required to confirm our findings and to better understand the mechanism involved in this association.

Acknowledgments This work has been supported by grants From the Ministerio de Economía y Competitividad (PI11/02505, AGL2010-22319-C03-03, CIBER06/03) and Fondo Europeo de Desarrollo Regional (PI061326 and PI070954) and by the Generalitat Valenciana, Spain (GVACOMP2011-151, ACOMP/2011/145 and ACOMP/2012/190), and Ministerio de Ciencia e Innovación (FPU) (AP2007-04663)

Conflict of interest None.

\section{References}

Abboud N, Ghazouani L, Saidi S, Ben-Hadj-Khalifa S, Addad F, Almawi WY et al (2010) Association of PAI-1 4G/5G and -844G/A gene polymorphisms and changes in PAI-1/tissue plasminogen activator levels in myocardial infarction: a casecontrol study. Genet Test Mol Biomarkers 14:23-27

Adamski MG, Turaj W, Slowik A, Wloch-Kopec D, Wolkow P, Szczudlik A (2009) 155.A-G-4G haplotype of PAI-1 gene polymorphisms $-844 \mathrm{G} / \mathrm{A}$, HindIII $\mathrm{G} / \mathrm{C}$, and $-6754 \mathrm{G} / 5 \mathrm{G}$ is associated with increased risk of ischemic stroke caused by small vessel disease. Acta Neurol Scand 120:94-100

Akhter MS, Biswas A, Ranjan R, Meena A, Yadav BK, Sharma A, Saxena R (2010) Plasminogen activator inhibitor-1 (PAI-1) gene $4 \mathrm{G} / 5 \mathrm{G}$ promoter polymorphism is seen in higher frequency in the Indian patients with deep vein thrombosis. Clin Appl Thromb Hemost 16:184-188

Al-Hamodi ZH, Saif-Ali R, Ismail IS, Ahmed KA, Muniandy S (2012) Plasminogen activator inhibitor-1 4G/5G polymorphism is associated with metabolic syndrome parameters in Malaysian subjects. J Clin Biochem Nutr 50:184-189

Arya R, Blangero J, Williams K, Almasy L, Dyer TD, Leach RJ, O'Connell P, Stern MP, Duggirala R (2002) Factors of insulin resistance syndrome-related phenotypes are linked to genetic 
locations on chromosomes 6 and 7 in nondiabetic MexicanAmericans. Diabetes 51:841-847

Berberoğlu M, Evliyaoğlu O, Adiyaman P, Ocal G, Ulukol B, Simşek $F$ et al (2006) Plasminogen activator inhibitor-1 (PAI-1) gene polymorphism (-675 4G/5G) associated with obesity and vascular risk in children. Pediatr Endocrinol Metab 19:741-748

Björck HM, Eriksson P, Alehagen U, De Basso R, Ljungberg LU, Persson K, Dahlström U, Länne T (2011) Gender-specific association of the plasminogen activator inhibitor-1 4G/5G polymorphism with central arterial blood pressure. Am J Hypertens 24:802-808

Boncoraglio GB, Bodini A, Brambilla C, Carriero MR, Ciusani E, Parati EA (2006) An effect of the PAI-1 4G/5G polymorphism on cholesterol levels may explain conflicting associations with myocardial infarction and stroke. Cerebrovasc Dis 22:191-195

Brown NJ, Murphey LJ, Srikuma N, Koschachuhanan N, Williams GH, Vaughan DE (2001) Interactive effect of PAI-1 4G/5G genotype and salt intake on PAI-1 antigen. Arterioscler Thromb Vasc Biol 21:1071-1077

Buckland G, González CA, Agudo A, Vilardell M, Berenguer A, Amiano P, Ardanaz E, Arriola L, Barricarte A, Basterretxea M, Chirlaque MD, Cirera L, Dorronsoro M, Egües N, Huerta JM, Larrañaga N, Marin P, Martínez C, Molina E, Navarro C, Quirós JR, Rodriguez L, Sanchez MJ, Tormo MJ, Moreno-Iribas C (2009) Adherence to the Mediterranean diet and risk of coronary heart disease in the Spanish EPIC Cohort Study. Am J Epidemiol 170:1518-1529

Dawson SJ, Wiman B, Hamsten A, Green F, Humphries S, Henney AM (1993) The two allele sequences of a common polymorphism in the promoter of the plasminogen activator inhibitor-1 (PAI-1) gene respond differently to interleukin-1 in HepG2 cells. J Biol Chem 268:10739-10745

Duggirala R, Blangero J, Almasy L, Dyer TD, Williams KL, Leach RJ, O'Connell P, Stern MP (2000) A major susceptibility locus influencing plasma triglyceride concentrations is located on chromosome $15 \mathrm{q}$ in Mexican Americans. Am J Hum Genet $66: 1237-1245$

Eliasson M, Jansson J-H, Nilsson P, Asplund K (1997) Increased levels of tissue plasminogen activator antigen in essential hypertension. A population-based study in Sweden. J Hypertens 15:349-356

Elosua R, Garcia M, Aguilar A, Molina L, Covas MI, Marrugat J (2000) Validation of the Minnesota leisure time physical activity questionnaire in Spanish women. Investigators of the MARATDON Group. Med Sci Sports Exerc 32:1431-1437

Eriksson P, Kallin B, van 't Hooft FM, Båvenholm P, Hamsten A (1995) Allele-specific increase in basal transcription of the plasminogen-activator inhibitor 1 gene is associated with myocardial infarction. Proc Natl Acad Sci 92:1851-1855

Estruch R, Martínez-González MA, Corella D, Salas-Salvadó J, RuizGutiérrez V, Covas MI, Fiol M, Gómez-Gracia E, López-Sabater MC, Vinyoles E, Arós F, Conde M, Lahoz C, Lapetra J, Sáez G, Ros E, PREDIMED Study Investigators (2006) Effects of a Mediterranean-style diet on cardiovascular risk factors: a randomized trial. Ann Intern Med 145:1-11

Fernández-Ballart JD, Piñol JL, Zazpe I, Corella D, Carrasco P, Toledo E, Perez-Bauer M, Martínez-González MA, SalasSalvadó J, Martín-Moreno JM (2010) Relative validity of a semi-quantitative food-frequency questionnaire in an elderly Mediterranean population of Spain. Br J Nutr 103:1808-1816

Fung TT, Rexrode KM, Mantzoros CS, Manson JE, Willett WC, Hu FB (2009) Mediterranean diet and incidence of and mortality from coronary heart disease and stroke in women. Circulation 119:1093-1100

Gohil R, Peck G, Sharma P (2009) The genetics of venous thromboembolism. A meta-analysis involving approximately
120,000 cases and 180,000 controls. Thromb Haemost 102:360-370

Gong LL, Peng JH, Han FF, Zhu J, Fang LH, Wang YH, Du GH, Wang HY, Liu LH (2012) Association of tissue plasminogen activator and plasminogen activator inhibitor polymorphism with myocardial infarction: a meta-analysis. Thromb Res 30:e43-e51

Grancha S, Estellés A, Tormo G, Falcó C, Gilabert J, España F et al (1999) Plasminogen activator inhibitor-1 (PAI-1) promoter 4G/ $5 \mathrm{G}$ genotype and increased PAI-1 circulating levels in postmenopausal women with coronary artery disease. Thromb Haemost 81:516-521

Ha H, Oh EY, Lee HB (2009) The role of plasminogen activator inhibitor 1 in renal and cardiovascular diseases. Nat Rev Nephrol 5:203-211

Hindorff LA, Schwartz SM, Siscovick DS, Psaty BM, Longstreth WT Jr, Reiner AP (2002) The association of PAI-1 promoter 4G/5G insertion/deletion polymorphism with myocardial infarction and stroke in young women. J Cardiovasc Risk 9:131-137

Kim KN, Kim KM, Kim BT, Joo NS, Cho DY, Lee DJ (2012) Relationship of plasminogen activator inhibitor 1 gene $4 \mathrm{G} / 5 \mathrm{G}$ polymorphisms to hypertension in Korean women. Chin Med J (Engl) 125:1249-1253

Kinik ST, Ozbek N, Yuce M, Yazici AC, Verdi H, Ataç FB (2008) PAI-1 gene 4G/5G polymorphism, cytokine levels and their relations with metabolic parameters in obese children. Thromb Haemost 99:352-356

Klinger KW, Winqvist R, Riccio A, Andreasen PA, Sartorio R, Nielsen LS, Stuart N, Stanislovitis P, Watkins P, Douglas R (1987) Plasminogen activator inhibitor type 1 gene is located at region q21.3-q22 of chromosome 7 and genetically linked with cystic fibrosis. Proc Natl Acad Sci 84:8548-8552

Kobashi G, Ohta K, Yamada H, Hata A, Minakami H, Sakuragi N, Tamashiro H, Fujimoto S, Hokkaido Perinatal Epidemiology Study Group (2009) 4G/5G variant of plasminogen activator inhibitor-1 gene and severe pregnancy-induced hypertension: subgroup analyses of variants of angiotensinogen and endothelial nitric oxide synthase. J Epidemiol 19:275-280

Kohler HP, Grant PJ (2000) Plasminogen-activator inhibitor type 1 and coronary artery disease. N Engl J Med 342:1792-1801

Landin K, Tengborn L, Smith U (1990) Elevated fibrinogen and plasminogen activator inhibitor (PAI-1) in hypertension are related to metabolic risk factors for cardiovascular disease. J Intern Med 227:273-278

Levy D, Larson MG, Benjamin EJ, Newton-Cheh C, Wang TJ, Hwang SJ, Vasan RS, Mitchell GF (2007) Framingham Heart Study 100K Project: genome-wide associations for blood pressure and arterial stiffness. BMC Med Genet 19(8 Suppl 1):S3

Li YY (2012) Plasminogen activator inhibitor-1 4G/5G gene polymorphism and coronary artery disease in the Chinese Han population: a meta-analysis. PLoS One 7:e33511

Lopes C, Dina C, Durand E, Froguel P (2003) PAI-1 polymorphisms modulate phenotypes associated with the metabolic syndrome in obese and diabetic Caucasian population. Diabetologia 46:1284-1290

Marchand A, Proust C, Morange PE, Lompré AM, Trégouët DA (2012) miR-421 and miR-30c Inhibit SERPINE 1 gene expression in human endothelial cells. PLoS One 7:e44532

Martínez-Calatrava MJ, González-Sánchez JL, Zabena C, MartínezLarrad MT, Luque-Otero M, Serrano-Ríos M (2007) Is the plasminogen activator inhibitor-1 gene a candidate gene predisposing to hypertension? Results from a population-based study in Spain. J Hypertens 25:773-777

Martínez-González MA, García-López M, Bes-Rastrollo M, Toledo E, Martínez-Lapiscina EH, Delgado-Rodriguez M, Vazquez Z, Benito S, Beunza JJ (2011) Mediterranean diet and the incidence of cardiovascular disease: a Spanish cohort. Nutr Metab Cardiovasc Dis 21:237-244 
Mataix J (2003) Tabla de composición de alimentos [Food composition tables]. University of Granada, Granada

Ossei-Gerning N, Mansfield MW, Stickland MH, Wilson IJ, Grant PJ (1997) Plasminogen activator inhibitor-1 promoter 4G/5G genotype and plasma levels of myocardial infarction in patients characterized by coronary angiography. Arterioscler Thromb Vasc Biol 17:33-37

Pérez-Martínez P, Adarraga-Cansino MD, Fernández de la Puebla RA, Blanco-Molina A, Delgado-Lista J, Marín C et al (2008) The $-6754 \mathrm{G} / 5 \mathrm{G}$ polymorphism at the plasminogen activator inhibitor 1 (PAI-1) gene modulates plasma plasminogen activator inhibitor 1 concentrations in response to dietary fat consumption. Br J Nutr 99:699-702

Poli KA, Tofler GH, Larson MG, Evans JC, Sutherland PA, Lipinska I, Mittleman MA, Muller JE, D'Agostino RB, Wilson PW, Levy D (2000) Association of blood pressure with fibrinolytic potential in the Framingham offspring population. Circulation 101:264-269

Rallidis LS, Gialeraki A, Merkouri E, Liakos G, Dagres N, Sionis D et al (2010) Reduced carriership of $4 \mathrm{G}$ allele of plasminogen activator inhibitor-1 $4 \mathrm{G} / 5 \mathrm{G}$ polymorphism in very young survivors of myocardial infarction. J Thromb Thrombolysis 29:497-502

Richardson K, Louie-Gao Q, Arnett DK, Parnell LD, Lai CQ, Davalos A, Fox CS, Demissie S, Cupples LA, FernandezHernando C, Ordovas JM (2011) The PLIN4 variant rs8887 modulates obesity related phenotypes in humans through creation of a novel miR-522 seed site. PLoS One 6:e17944

Ruiz-Quezada S, Vázquez-Del Mercado M, Parra-Rojas I, RangelVillalobos H, Best-Aguilera C, Sánchez-Orozco LV, MuñozValle JF (2004) Genotype and allele frequency of PAI-1 promoter polymorphism in healthy subjects from the west of
Mexico. Association with biochemical and hematological parameters. Ann Genet 47:155-162

Sawathiparnich P, Murphey LJ, Kumar S, Vaughan DE, Brown NJ (2003) Effect of combined AT1 receptor and aldosterone receptor antagonism on plasminogen activator inhibitor-1. J Clin Endocrinol Metab 88:3867-3873

Schoenhard JA, Asselbergs FW, Poku KA, Stocki SA, Gordon S, Vaughan DE et al (2008) Male-female differences in the genetic regulation of t-PA and PAI-1 levels in a Ghanaian population. Hum Genet 124:479-488

Schröder H, Fitó M, Estruch R, Martínez-González MA, Corella D, Salas-Salvadó J, Lamuela-Raventós R, Ros E, Salaverría I, Fiol M, Lapetra J, Vinyoles E, Gómez-Gracia E, Lahoz C, SerraMajem L, Pintó X, Ruiz-Gutierrez V, Covas MIA (2011) Short screener is valid for assessing Mediterranean diet adherence among older Spanish men and women. J Nutr 141:1140-1145

Seguí R, Estellés A, Mira Y, España F, Villa P, Falcó C, Vayá A, Grancha S, Ferrando F, Aznar J (2000) PAI-1 promoter 4G/5G genotype as an additional risk factor for venous thrombosis in subjects with genetic thrombophilic defects. Haematology 111:122-128

Spiroski I, Kedev S, Antov S, Trajkov D, Petlichkovsk A, DzhekovaStojkova $S$ et al (2000) Investigation of SERPINE1 genetic polymorphism in Macedonian patients with occlusive artery disease and deep vein thrombosis. Kardiol Pol 67:1088-1094

Tabak O, Gelisgen R, Uzun H, Kalender B, Balci H, Curgunlu A et al (2009) Hypertension and hemostatic/fibrinolytic balance disorders. Clin Invest Med 32:E285

Trichopoulou A, Costacou T, Bamia C, Trichopoulos D (2003) Adherence to a Mediterranean diet and survival in a Greek population. N Engl J Med 348:2599-2608 